\title{
Features and results of assessment the thermal conductivity of building materials and products by the active method of thermal non-destructive testing
}

\author{
Denis Karpov 1,*, Mikhail Pavlov ${ }^{1}$, Liliya Mukhametova², Anton A. Mikhin ${ }^{3}$ \\ ${ }^{1}$ Vologda State University, Lenina Street 15, Vologda, 160000, Russia \\ ${ }^{2}$ Kazan State Power Engineering University, str. Krasnoselskaya, 51, 420066, Kazan, Russia \\ ${ }^{3}$ Peter the Great St. Petersburg Polytechnic University, Saint Petersburg, Russia
}

\begin{abstract}
Thermal control (passive and active) is a non-destructive testing method. During passive thermal control, the test object is characterized by a temperature field formed during its operation. In active thermal control, the test object is additionally thermally stimulated. This technique is widely used in various areas of construction, energy, mechanical engineering, transport. This paper proposes a variant of active thermal non-destructive assessment of the thermal conductivity coefficient of building materials and products on the example of a fragment of a building structure made of silicate bricks. The test object is subjected to thermal stimulation by an external source of thermal energy before reaching a steady-state thermal regime. Thermography of the test object surfaces is carried out. The average integral temperatures of surfaces or individual sections of the test object are calculated. The coefficient of thermal conductivity of the test object is determined, which is used to calculate its thermal resistance (resistance to heat transfer). After that, the coefficient of heat transfer is calculated. The method was implemented in laboratory conditions. It can be used in natural and operational conditions for accurate and quick determination of the key thermophysical properties of building materials and products.
\end{abstract}

\section{Introduction}

The experimental methods for assessing the quality, durability, reliability and safety of traditional and modern building materials and products are characterized by a vast variety and complexity [1-7]. So, the issues of developing new and improving the existing meth-ods and means of thermal control (TC) and technical diagnostics (TD) are of urgent im-portance [817]. The methods and means of TC and TD are used to determine the listed characteristics of the investigated building materials and finished products according to their thermophysical properties (TPP) $[10,11,18]$, namely: thermal conductivity, thermal diffusivity, heat capacity, thermal activity, heat resistance, etc. [18].

Further we consider basic terms and definitions used in this work, which are stated in the regulatory documents (national standards) of the Russian Federation.

Non-destructive testing is a field of science and technology that encompasses the study of physical principles, the development, improvement and application of methods, means and technologies for technical control of objects that do not destroy or worsen their serviceability. Thermal non-destructive testing is the non-destructive testing based on the registration of temperature fields of the test object. The active method of thermal non-destructive testing is a method of thermal non-destructive testing, in which the test object is thermally stimulated by an external source of thermal energy. Non-contact thermometry is a set of methods and means for measuring temperature based on noncontact and remote measurement of thermal radiation from the surface of a test object.

Thermal imager is a device designed to examine heated test objects by their own ther-mal radiation. The thermal imager converts infrared radiation invisible to the human eye into electrical signals, which, after amplification and automatic processing, are again converted into a visible image of the test objects. Thermal imaging (control, inspection, moni-toring) is a set of technological operations aimed at measuring the temperature field of the monitored object by the noncontact thermometry using a thermal imager in order to detect thermal technical defects. Thermogram is a thermal image of the test object or its separate section. Temperature field is a set of instantaneous temperatures at all points on the surface of the test object or its section.

This paper proposes a variant of active thermal nondestructive assessment of the ther-mal conductivity coefficient of building materials and products in a stationary thermal regime. It simplifies the technical procedure for determining the thermal conductivity and expands the possibilities of studying the heat-conducting

* Corresponding author: karpov denis $85 @$ mail.ru 

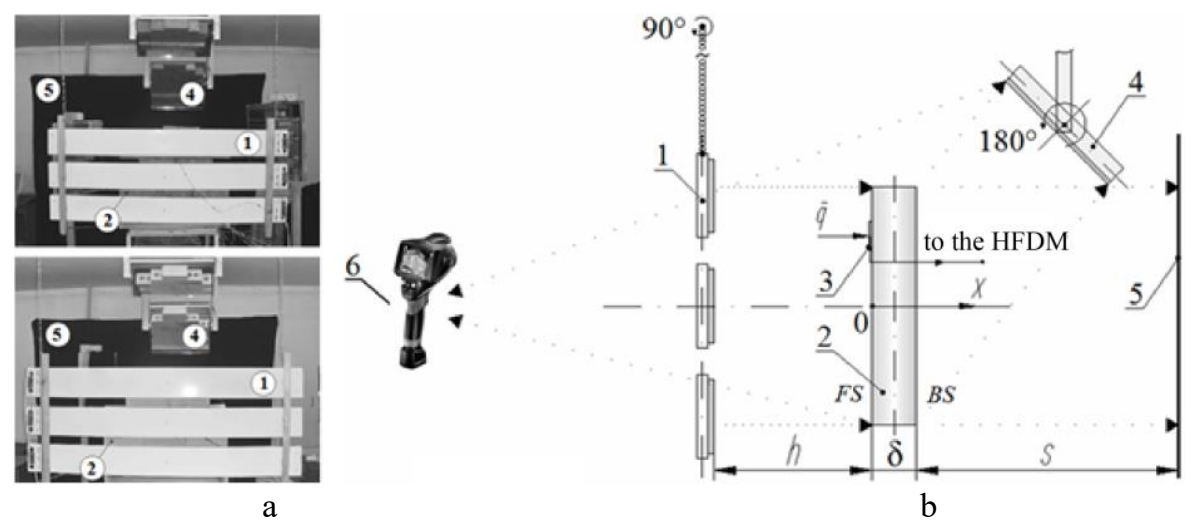

Fig. 1. External view of the setup (a) and the scheme of the method implementation (b): 1 - source of thermal stimulation; 2 - test object (TO); 3 - heat flux density converter; 4 - mirror reflector; 5 - light-absorbing screen; 6 - thermal imager. $q$ is the density of the heat flux falling on the front surface (FS) of the TO; $h$ is the distance between the heating surface of the thermal stimulation source (1) to the front surface (FS) of the TO; FS is the front surface of the TO; BS is the back surface of the TO (2); $S$ is the distance between the BS and the surface of the light-absorbing screen (5); $\delta$ is the thickness of the TO; HFDM is the heat flow density meter.

properties of non-uniform single-layer building structures.

\section{Materials and methods}

The advantage of the considered method is the noncontact remote determination of temperature fields of the test object surfaces. They are further used to determine the thermal conductivity coefficients of individual elements and of the entire structure as a whole, regardless of its thermal engineering heterogeneity. The conditions for the implementation of the method do not depend on external environmental factors and are completely determined by the modes of heat exchange between the source of thermal stimulation and the test object. The thermal imager and the mirror reflector, in the field of view of which the rear surface of the test object falls, enable assessing the temperature states of both surfaces of the test object with a short time interval, almost simultaneously. This reduces the measurement error and increases the accuracy of the entire experiment when implementing the method. The analytical expression for establishing the initial moment of the stationary thermal regime of the test object has a simple mathematical form. It can significantly reduce the measurement time and ensure high reliability of the obtained experimental results.

The described technique is implemented using the experimental setup, Figure 1.

The technique is implemented according to the following algorithm:

1. The test object 2 is thermally stimulated by an external source of thermal energy 1 until it achieves a steady-state thermal regime.

2 . The time $\tau, \mathrm{s}$ of reaching the stationary thermal regime by the test object 2 is calculated according to the analytical expression:

$$
\tau=\frac{\delta^{2}}{a}
$$

where $\delta$ is the width of the test object $2, \mathrm{~m} ; a$ is the preset thermal conductivity of the test object $2, \mathrm{~m}^{2} / \mathrm{s}$.

3 . Thermography of both surfaces of the control object 2 is carried out at a steady-state stationary thermal regime from the time moment $\tau$.

4. The mean integral temperatures of the front surface (FS) $t_{0}$ and the back surface (BS) $t_{\delta}$ or individual sections of the test object are determined in the coordinates $x=0$ and $x=\delta$, respectively.

5. The thermal conductivity coefficient of the test object $\lambda_{t}, \mathrm{~W} /\left(\mathrm{m}^{\circ}{ }^{\circ} \mathrm{C}\right)$ is calculated according to the thermal conductivity equation for a flat wall at a stationary thermal regime:

$$
\lambda_{t}=\frac{q \delta}{\left(t_{0}-t_{\delta}\right)}
$$

where $q$ is the density of the heat flux falling on the front surface (FS) of the TO for $x=0$ according to the data from the heat flow density meter (HFDM) $3, \mathrm{~W} / \mathrm{m}^{2} ; \delta$ is the thickness of the TO 2, m.

6. With a known coefficient of thermal conductivity $\lambda_{t}, \quad \mathrm{~W} /\left(\mathrm{m} \cdot{ }^{\circ} \mathrm{C}\right)$, one calculates the actual thermal resistance (resistance to heat transfer) $R, \mathrm{~m}^{2} \cdot{ }^{\circ} \mathrm{C} / \mathrm{W}$, of the test object using the analytical expression:

$$
R=\frac{\delta}{\lambda_{t}}
$$

where $\delta$ is the test object thickness, $m ; \lambda_{t}$ is the coefficient of thermal conductivity of the test object, $\mathrm{W} /\left(\mathrm{m} \cdot{ }^{\circ} \mathrm{C}\right)$.

\section{Results and discussion}

This method was used to assess thermal characteristics of a fragment of a building envelope in the form of a wall of silicate bricks (3-hollow building brick M150) according to the algorithm presented in the previous section. 
Table 1. Data from thermography of wall surfaces.

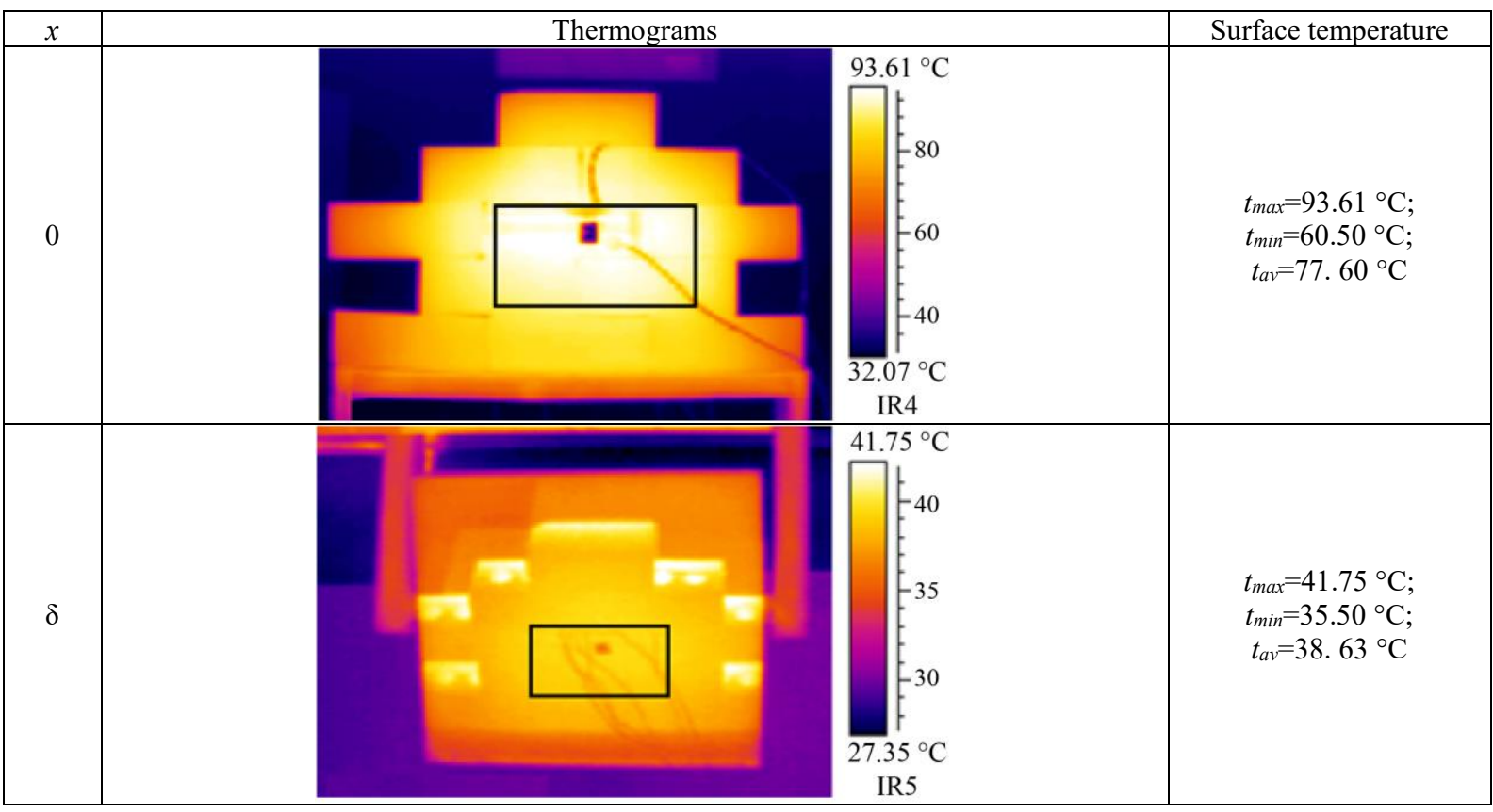

Table 2. Calculated coefficients of thermal conductivity and thermal resistance of the wall.

\begin{tabular}{|c|c|c|c|c|c|c|}
\hline No. & $q, \mathrm{~W} / \mathrm{m}^{2}$ & $\delta, \mathrm{m}$ & $t_{0},{ }^{\circ} \mathrm{C}$ & $t_{\delta},{ }^{\circ} \mathrm{C}$ & $\lambda_{t}, \mathrm{~W} /\left(\mathrm{m} \cdot{ }^{\circ} \mathrm{C}\right)$ & $R, \mathrm{~m}^{2} \cdot{ }^{\circ} \mathrm{C} / \mathrm{W}$ \\
\hline 1 & \multirow{3}{*}{370} & \multirow{3}{*}{0.12} & 93.5 & 39.0 & 0.81 & 0.147 \\
\hline 2 & & & 93.3 & 38.0 & 0.80 & 0.149 \\
\hline 3 & & & 93.1 & 36.0 & 0.78 & 0.154 \\
\hline \multicolumn{5}{|c|}{ Average values of $\lambda_{t}, \mathrm{~W} /\left(\mathrm{m} \cdot{ }^{\circ} \mathrm{C}\right)$ and $R,\left(\mathrm{~m}^{2} \cdot{ }^{\circ} \mathrm{C}\right) / \mathrm{W}$} & 0.80 & 0.150 \\
\hline
\end{tabular}

1. Thermal stimulation of the wall was performed by a source of infrared radiation - the Ecoline ELK 10R electric infrared emitters with a total power of $\mathrm{N}=3 \mathrm{~kW}$.

2. The thermal diffusivity of the silicate brick was taken from the reference book $a=5.3 \cdot 10^{-7} \mathrm{~m}^{2} / \mathrm{s}$. Then, in accordance with (1), the beginning of the wall reaching the stationary thermal regime is $\tau=27170 \mathrm{~s}$ (the experimental value is $\tau^{\prime}=30000 \mathrm{~s}$ ).

3 . Thermography of the wall surfaces was carried out with the Testo 875-2 thermal imager three times at regular intervals. The choice of thermograms was carried out taking into account the quality of thermal images, which give the most complete and accurate information about the temperature field of the wall surfaces (Table 1).

4. The mean integral temperatures of individual sections $t_{0}$ of the FS and $t_{\delta}$ of the BS of the wall were determined in coordinates $x=0$ and $x=\delta$, respectively, (Table 2).

5 . The coefficient of thermal conductivity of the wall was calculated according to (2) (Table 2).

6 . The thermal resistance of the wall was calculated according to (3) (Table 2).

The calculated thermal conductivity coefficient of a fragment of a building envelope in the form of a silicate brick wall was $0.80 \mathrm{~W} /\left(\mathrm{m}^{\circ}{ }^{\circ} \mathrm{C}\right)$, which is consistent with the standard value equal to $0.82 \mathrm{~W} /\left(\mathrm{m}^{\circ}{ }^{\circ} \mathrm{C}\right)$.

\section{Conclusions}

The proposed method makes it possible to determine the actual thermal conductivity coefficient of building materials and products during the research, control, assessment, laboratory, bench, full-scale and operational tests. Further the obtained values can be used to calculate the actual thermal resistance (resistance to heat transfer) of the enclosing structures of buildings and structures.

The thermal resistance (resistance to heat transfer) of enclosing structures allows one to quantitatively assess the thermal technical qualities of building structures and constructions. It helps to assess their compliance to regulatory requirements, to establish real heat losses through external enclosing structures, and to check the design solutions.

\section{References}

1. G. Dall'O', L. Sarto, A. Panza, Infrared screening of residential buildings for energy audit purposes: Results of a field test, Energies (2013)

2. E. Kuzin, B. Gerike, V. Shachmanov, Criteria Justification for Assessing the Technical Condition of Gearboxes of Mining Machines Based on Infrared Thermography, E3S Web of Conferences (2020) 
3. R. Zhou, X. Zha, C. Wang, Numerical study on temperature field of the sandwich plate defects based on MATLAB, E3S Web of Conferences (2020)

4. I. Ullah, F. Yang, R. Khan, L. Liu, H. Yang, B. Gao, K. Sun, Predictive maintenance of power substation equipment by infrared thermography using a machine-learning approach, Energies (2017)

5. R. Usamentiaga, P. Venegas, J. Guerediaga, L. Vega, J. Molleda, F.G. Bulnes, Infrared thermography for temperature measurement and non-destructive testing, Sensors (Switzerland) (2014)

6. C.A. Balaras, A.A. Argiriou, Infrared thermography for building diagnostics, Energy Build (2002)

7. C. Meola, G.M. Carlomagno, Recent advances in the use of infrared thermography, Meas. Sci. Technol. (2004)

8. V.V. Klyuev, O.N. Budadin, E.V. Abramova, Thermal inspection of composite structures in terms of power and shock loading (Publishing House "SPECTRUM", 2017)

9. A.A. Sinitsyn, D.F. Karpov, M.V. Pavlov, Basic Thermal Imaging Diagnostics of Heat-Consuming Construction Facilities (VoSU, 2014)

10. D. Karpov, A. Sinitsyn, Algorithm for Integrated Non-Destructive Diagnostics of Technical Condition of Structures of Buildings and Constructions Using the Thermogram Analysis, E3S Web Conf. 161 (2020)

11. D.F. Karpov, M.V. Pavlov, A.A. Sinitsyn, Integrated energy-saving diagnostics of the technical condition of fencing structures of capital construction objects and engineering systems based on thermal control, Sci. Tech. J. "Energy Sav. water Treat. 2 (124) 29-33 (2020)

12. G.K. Vijayaraghavan, M.C. Majumder, K.P. Ramachandran, NDTE using flash thermography: Numerical modelling and analysis of delaminations in GRP pipes Insight Non-Destructive Test. Cond. Monit. 52 481-487 (2010)

13. S. George, S. Goravar, D. Mishra, M.T. Shyamsunder, P. Sharma, G.K. Padmashree, P.S. Kumar, P. Bremond, K. Mukherjee, Stress monitoring and analysis using lock-in thermography Insight Non-Destructive Test. Cond. Monit. 52 470474 (2010)

14. K.E. Cramer, W.P. Winfree, K. Hodges, A. Koshti, D. Ryan, W.W. Reinhardt, Status of thermal NDT of space shuttle materials at NASA Thermosense XXVIII 6205 62051B (2006)

15. S. Goutam, J.M. Timmermans, N. Omar, P. Van den Bossche, J. Van Mierlo, Comparative study of surface temperature behavior of commercial li-ion pouch cells of different chemistries and capacities by infrared thermography, Energies (2015)

16. A.D. Zaripova, D.K. Zaripov, A.E. Usachev, Automatic condition monitoring method to find defects in high-voltage insulators using infrared images, E3S Web of Conferences (2019)

17. D.S.Choi, M.J. Ko, Comparison of various analysis methods based on heat flowmeters and infrared thermography measurements for the evaluation of the in situ thermal transmittance of opaque exteriorwalls, Energies (2017)

18. O.N. Budadin, V.P. Vavilov, E.V. Abramova, Thermal control (Publishing House "SPECTRUM", 2013).

19. D. Mazhitov, M. Ermilova, E. Altukhova, T. Maksimova, and O. Zhdanova, Development of Technologies and Processes in Environmental Management, E3S Web of Conferences 135, 04045 (2019). doi:10.1051/e3sconf/201913504045. 